Euskal ikerketen aldizkaria | Revue d'études basques |

Revista de estudios vascos | Basque studies review

$13 \mid 2009$

Numéro XIII

\title{
Bi datibo egitura ifar-ekialdeko zenbait hizkeratan
}

Ricardo Etxepare et Bernard Oyharçabal

URL : http://journals.openedition.org/lapurdum/2049

DOI : 10.4000/lapurdum.2049

ISSN : 1965-0655

Éditeur

IKER

Édition imprimée

Date de publication : 1 février 2009

Pagination : 145-158

ISBN : 978-2-86781-409-X

ISSN : $1273-3830$

\section{Référence électronique}

Ricardo Etxepare eta Bernard Oyharçabal, « Bi datibo egitura ifar-ekialdeko zenbait hizkeratan »,

Lapurdum [Linean], 13 | 2009, Sarean emana----an 15 avril 2013, kontsultatu 03 mai 2019. URL : http:// journals.openedition.org/lapurdum/2049; DOI : 10.4000/lapurdum.2049 


\title{
Bi datibo egitura ifar-ekialdeko zenbait hizkeratan
}

\author{
Ricardo ETXEPARE eta Bernard OYHARÇABAL \\ CNRS-IKER
}

\section{Sarrera}

Ekialdeko zenbait hizkeratan, ohikoa da datiboa lekuzkoak iduri duten roletan aurkitzea: ${ }^{2}$

(1) a. Jaun erretora badoa elizako atearen gakoari

b. Balkoin bat, bideari emaiten duena (Etc. OM, 130)

c. Alemanen tankak oldartzen zirela ... Maginot harresiari (Lz, VII, 53)

d. Hurbiltzen da poliki-poliki bonetari

Erdialdeko eta mendebaldeko hizkeretan era horretako rolak leku postposizioen bitartez gauzatzen dira:

(2) a. Jaun erretora badoa elizako ate gakorantz/gakora

b. Balkoi bat, bidera ematen duena

c. Alemanen tankeak oldartzen zirela Maginot harresiaren kontra

d. Hurbiltzen da poliki-poliki txapelera/txapelaren ingurura

Leku datiboez aparte, ekialdeko hizkera berek badute txandakatzea deitu genezakeen zerbait datibo komunztaduraren eremuan (Oyharçabal, 1992; Ortiz de Urbina, 1995; Etxepare eta Oyharçabal, 2009; Fernandez eta Ortiz de Urbina, 2008). Ikus esate baterako pare minimotzat jo ditzakegun ondoko kasuak:

(3) a. Ez dezagun goizegi harria bota dohakabe horier!

(Etc.OM, 41)

b. Orduan furia gorrian sartzen da, eta botatzen dio saindu-gaiari ...aulki bat (Etc.FE, 62)

1. Lan hau hiru proiekturen laguntzaz egin da: ANRko TSABL proiektua (ANR-07-CORP-033), MCIko FFI 2008-00240 proiektua, eta Eusko Jaurlaritzaren ikerketa taldeak laguntzeko beka baten bitartez (GIC07/144IT-210-07).

2. Etsenpluen iturburuen berri jakiteko ikus 2. atala 
Artikulu honek bi fenomeno horiek lotuta daudela defendatzen du. Lau dira lotura hori egitea ahalbidetzen duten hipotesiak:

a. Ekialdeko hizkerek badituzte bi estrategia Hartzaile eta Helmuga rolak adierazteko: (i) bata postposizio bidezkoa, «leku-datibo» deitu ditugun horietan erakutsian gelditzen dena; eta bestea (ii) aplikatiboa deituko dugun bat, buru funtzional jakin baten bitartez gauzatzen dena perpaus egituran, eta baldintza semantiko berezi batzu ezartzen dituena (ikus baitaere Oyharçabal, 2008).

b. «Lekuzkoa» deituko dugun datiboak, adposizioen interpretazioaren esparruan ibilbide hesitugabea (unbounded path) deitzen dena denotatzen du (Jackendoff, 1983, 1990, 1991; Higginbotham, 2001; Huijbregts eta van Riemsdijk, 2001; van Riemsdijk, 2007; Svenonius, 2004; Zwarts, 2005; Ramchand, 2008, besteak beste).

c. Lekuzko datibo hau aspektuaren esparrura ere hedatzen da, eta bertan lekuzko adierarekin lot daitekeen balio bat dauka: datiboz markaturiko elementuak ez dezake berez egoera aldaketa baten edo ibilbide baten amaiera puntua adierazi.

d. Horrenbestez, (3)ko txandakatzea ez da segitzen komunztaduraren balizko hautazko izaeratik. Haren azpian bi egitura desberdin daude: bata postposizionala eta bestea aplikatiboa. Alde honetatik, ekialdeko hizkera hauetan aurkitzen dugun txandakatzea Ingelesez (eta beste hainbat hizkuntzatan) aspaldi ezaguna den Double Object Construction/Prepositional Object Construction txandakatzearen parekoa da, zenbait ikerlarik eman dioten interpretazioan (ikus horretarako Anagnastopoulou, 2003; Bleam, 1999; Cuervo, 2003; Harley, 2003 ; Romero, 1997; Levin, 2008, besteak beste).

\section{Lan korpusa}

Ondoan datozen eztabaida eta ondorioak korpus jakin baten gainean oinarriturikoak dira. Korpus horrek XX. mendearen bigarren erdiko ekialdeko hiru idazleren lanak biltzen ditu: Piarres Lartzabal, Jean-Baptiste Etcheberry eta Etienne Sallaberry. Ikus erreferentziak. Tarteka hizkera horietako egungo hiztunak, eta bestelako idatzizko lanak ere baliatu ditugu. Halakoetan, etsenpluaren iturburua ere jaso dugu. Hemengo gaien tratamendu zabalago baterako, ikus Oihartzabal (2008), Etxepare eta Oihartzabal (2009a,b), Etxepare (prestatzen), eta Fernandez eta Ortiz de Urbina (2008).

\section{LEHEN ATALA}

\section{Leku datiboak noiz}

Zerk mugatzen du ekialdeko « leku-datibo » hauen distribuzioa?

\subsection{Mugimendu helburudunezko aditzak}

Datiboaren kontribuzioa garbiago ikusiko da kasu konkretu bati helduaz. Hartu itzuli aditza. Aditz honek bi adiera ditu gure korpusean: batetik «hasierako lekura bueltatzea» esan nahi du; bestetik «zerbaiti begira jartzea». Lehen adieran, itzuli aditzak alatibozko helmuga hartzen du (3), erdialde eta mendebaldeko hizkeretan bezalaxe. «Zerbaiti buruz/zerbaiti begira jartzea» adierazten duenean berriz, datibozko jomuga bat hartzen du (4a):

(3) a. Etxera itzuli da

b. *Etxeari itzuli da

(4) a. Bizkarrez itzultzen da urari (Elizalde, Artho-xuriketan, armiarma.com-etik) 


\section{b. Bizkarrez itzultzen da uretarat}

(4a) eta (4b) konparatzen baditugu, bada adiera aldetik biak bereizten dituen zerbait: (4a) perpausak subjektua urari bizkar emanez jarri dela adierazten du, gorputza hartarako jiratuaz; (4b) perpausak berriz, subjektua ura dagoen aldera gibelka mugitu dela esan nahi du.

Itzuli aditzaren bi adiera horiek kontzeptu eskema diferenteak errepresentatzen dituzte. Jackendoffen (1990) errepresentazio sistema baliatuaz, bigarren adiera hori honela eman genezake:

(5) Itzuli "Norbaiti/zerbaiti begira jartzea"

a. $\left[_{\text {EVENT }} \operatorname{INCH}\left(\left[\right.\right.\right.$ ORIENT $\left.\left.\left(\left[_{\text {Thing }} \ldots\right],\left[\left[_{\text {Path }} \ldots\right]\right)\right]\right)\right]$

b. [ [EVENT INCH ( [ORIENT ([ ${ }_{\text {Thing }}$ Subjektua], [ [ Path Ura])])]

"Hasierako lekura bueltatu" adierak JOAN oinarrizko funtzio kontzeptuala duen bitartean, "norbaiti/zerbaiti begira jartzeak" NORANZKOA oinarrizko funtzioa dauka (Jackendoff-en sistemako ORIENT), eta honek ez du helmuga jakin baterainoko mugimendua galdatzen. Kontraste honek ondoko hipotesirako bidea ematen digu: leku datiboa deitu dugun hori helmugaratze bat adierazten ez duten mugimendu aditzekin agertzen da. Itzuli-ren kasuan, aditzak "x y-ri begira jartzea" adierazten duenean, eventuak ez du Gaia Helmugaraino eramaten. Datiboaren zeregina hori markatzea da. Helmuga terminoak berak desegokia ematen baitu kasu hauetan, Jomuga terminoa erabiliko dugu aurrerantzean NORANZKO funtzioaren leku argumentua adierazteko.

Itzuli bezala azter daiteke baitaere bihurtu aditza, bi adiera dituena gure korpusean: batetik "lehengora ekarri, bilakatu", bestetik "zerbaiti aurre egin". Datibo markaren presentziak bereizten ditu bi adiera horiek:

(6) a. Gaizkira bihurtu da

b. Gaizkiari bihurtzen delarik

(6a) etsenpluak norbait gaizkira itzuli dela esan nahi du. (6b)k berriz norbaitek gaizkiari buru egiten diola.

Mugimendu aditzen sailean jarraituaz, abiatu aditzak «helmuga jakin batera joateko mugimendua egin» adieraz dezake, edo «bidean jartzea» besterik gabe. Datibodun kasuak bigarren adiera honetan bakarrik ulertzen ahal dira (7b):

\section{(7) a. Bidera abiatu da}

b. Bideari abiatu da

Alatibozko postposizioarekin predikatuak mugimendu bat adierazten du Gaia leku fisiko batera eramaten duena. Leku fisiko hori bidea da. Datiboarekin berriz subjektua abian jarri dela esan nahi dugu, bidea ez delarik helmuga, baizik eta subjektuak unean-unean ibiltzen duen espazio-tarte bat.

Beste horrenbeste gertatzen da joan aditzarekin, ondoko kontrastearen arabera: ${ }^{3}$

3. (8a) Larzabalen lanetik harturiko etsenplu bat da. (8b) Bernat Oihartzabalen juzkuari dagokio. 
(8) a. Jaun erretora badoa elizako atearen gakoari

b. \#Jaun erretora badoa elizako atearen gakora

(Ekialdean)

(8b)-k ekialdeko hizkeretan, erretorak atearen gakoan bukatuko duela aditzera ematen du. Pragmatikoki beraz, ezin onartuzkoa da. (8a)-k ez du irakurketa hori. Lartzabalen testuari begiratuta, erretora atearen gakoari buruz mugitzen dela esan nahi du.

Erori aditzak ere antzeko pareak osatzen ditu:

(9) a. Lurrera erori da

b. Jainkoaren nahi sainduari erortzen diren arima jenerosak (Etc. BEB, 109)

Lehen kasuan, erori aditzak leku fisiko batean gertatzen den erorketa arrunta adierazten du. Bigarren kasuan, aldiz, "zerbaiti buruz makurtu” esan nahi du.

Kontraste horien barnean ulertu behar dira halaber mugimendu jomugaduna adierazten duten adizki ateliko edo burutugabeekin komunztadurarik gabe agertzen diren datiboak, hala nola jarraiki/segitu edo hurbildu aditzei dagozkienak. Aditz hauek ez dute helmuga jakin batean bukatzen den mugimendurik adierazten:

(10) a. Etsenplu oneri... jarraiki da bere debozionezko urhatsetan

b. Hurbiltzen da polliki bonetari

Hau baldin bada leku-datiboen azpian dagoena, ulertzen has gintezke zergatik zenbait predikatu klasek ez duten sekula halako datiborik erakusten: ez etorri/jin (11) ez eta heldu (12) aditzak ere ez dute leku datiborik hartzen. Biek ere buruturiko mugimendu bat adierazten dute, gaia helmuga jakin bateraino eramaten duena.

(11) *Etxeari liburua heldu da

(12) *Etxeari eskale bat etorri/jin da

\subsection{Jarrera-aldaketa aditzak}

Hartu orain ondoko aditzak:

(13) a. Heien egitateeri begiak hetsi ditut

(LZ., II, 74)

b. Aphal dezagun burua jainkoaren nahi sainduari

(Etc. FE, 179)

c. Ederrak idekitzen du gogoa egiari

(Sal. 180)

d. Haien erranari behar dugu nahitaez plegatu

Kasu guzietan, absolutibozko argumentuak egoera aldaketa bat jasaiten du, eta egoera aldaketa hori datibozko argumentuari buruz (jomuga abstraktu bat) gertatzen da. Baina ez dago mugimendurik absolutibodun argumentua hartu eta helmugaraino eramaten duenik. Aitzitik, iduri du absolutibozko objektua dela datibozkoaren bidean paratzen dena, hura trabatuz. Goiko predikatu guziak honela deskriba daitezke: datiboak adierazten duen zerak badu ekiteko joera bat, absolutiboak nola edo hala zaildu egiten duena.

\section{Leku datibotik aspektura}

\subsection{Iharduera aditzak}


Leku datiboak helmugarainoko lekualdatze bat adierazten ez duten mugimendu aditzekin agertzen dira. Aspektu mailan, horren ordaina aditz atelikoak dira, berezko bukaera punturik erakusten ez duten aditzak. Sail honen barnean iharduera aditzak daude: ihardoki, jo, eta pentsatu, besteak beste.

(14) a. Bainan herriak ez dezake ihardok ikastegiari

b. Athe guzieri jotzen du

c. Biharkoari pentsatzen diat

Aditz hauek iharduera bat adierazten dute, eta iharduera horrek ez du berezko bukaera punturik. Ihardoki eta pentsatu-ren kasuan nabarmena da. Jo-ren kasuan interesgarria da ikustea zein kontestutan agertzen den datiboa. Jo bezalako aditz batek irakurketa bat baino gehiago izan dezake. Baina datibozko jomuga batez lagunduta agertzen den guzietan adiera semelfaktiboa da. Eman dezagun esate baterako, otoa aparkatu nahi dugula. Entseiatzera gindoazelarik atzeko horma jo dugu. (15a), datibo batekin, ez da posible kontestu horretan. Lekuzko argumentuak postposizio baten bitartez (15b) edo absolutiboz markatua agertu behar du (15c): ${ }^{4}$

(15) a. *Otoak hormari jo du

b. Otoak horman jo du

c. Otoak horma jo du

(14b) perpausa aldiz posible da jo aditzak bertan berezko bukaera punturik gabeko ekintza bat adierazten duelako. Norbaiten atean ate-joka ibiltzea ez da berez bukatzen den zerbait. Nahi adina luza daitekeen gertakaria da. Kotxe batek zerbaiten kontra jotzen duenean berriz, jotze horrek berak ekartzen du eventuaren bukaera. ${ }^{5} \quad$ Beste ekintza aditz batzu, hala nola jazarri edo oldartu, ekintzaren hasiera puntua markatzen dute, baina ez dute ekintza hori bukatu egiten den berezko mugarik adierazten. Aditz hauek komunztaduragabeko datiboa agertzen dute eskuarki:

(16) a. Egia da jazarri zirela erregearen manuari?

(LZ. IV, 152)

b. Alemanen tankak oldartzen zirela Maginot harresiari

\subsection{Aspektu aditzak}

Aspektu aditz atelikoek komunztaduragabeko datibozko osagarriak hartzen dituzte komunzki:

(17) a. Ari zen murtza-murtza tabakorik gabeko pipa handiari

(Sal. 145)

b. Ordu berean abiatu zen fraide muthilak biltzeari

(Etc. OM, 106)

c. Horren hedatzeari bermatzen zen

(Etc. OM, 222)

d. Jarraikiko naiz arrosario sainduaren erraiteari

(Etc.HH, 39)

e. Laster jarri nintzen eskol emaiteari

(Etc, B)

4. Eskerrak eman nahi dizkiogu Celine Mounhole-ri honen inguruko eztabaida eta intuizioengatik.

5. Horrek ez du esan nahi, bistan da, ezin errepika daitekeenik. 
Aspektu aditz atelikoek bakarrik dute ahalmen hori. Bestelako aspektu aditzek, hala nola bukatu edo lortu, lorkuntzak adierazten dituztenak, ez dute datibozko osagarririk hartzen:

(18) a. *Bukatu du egiteari

b. *Lortu zuen egiteari

\section{Egoera aditzak}

Egoera aditz hutsak helmugaratzerik edo emaitza-egoerarik gabeko beste aditz prototipikoak dira. Sail honetan ere leku-datiboak agertzen dira:

(19) a. Balkoin bat, ... bideari emaiten duena

(Etc.OM, 130)

b. Erne egon momentuaren kausitzeari

(LZ. II, 62)

d. Fida zaitezte eni

e. Guri da egiazko euskalduna Euskal Herrian sor-araztea

f. Jakitatea zor da guzieri, baina lehenik gazteeri

g. Descartes izan dena gogo argituari, Freud izan da gogo ez ezagutuari

h. Neri tokatzen direnak, zuretako fitsik ez dira

i. Zure etorkizunari gomeni ez diren molde herrestarat...

Aurreko kasuen analisi kontzeptualaren bidetik, aditz horiek Jackendoff-ek berak jasotzen duen ondoko errepresentazioaren bitartez adierazi daitezke (Jackendoff, 1983:173):

(20) $\left[_{\text {State }} \operatorname{ORIENT}\left(\left[_{\text {Thing }} \mathrm{x}\right],\left[_{\text {Path }} \mathrm{y}\right]\right)\right]$

(20)ko formulak ondoko perpausak jasotzen ditu ingelesez:

(21) a. The sign points to Philadelphia

b. The house faces the mountains

c. The cannons aim through the tunnel

(21) bezalako perpausek ez dute subjektuaren lekua deskribatzen, baizik eta hura zeri buruz paratua dagoen. Preposizio sintagma ibilbide-funtzio bat da, subjektuaren orientazioa zehazten duena. 3.1 ataleko errepresentazioarekin alderatuta (22a), (20)koa ez da eventu bat, eta ez du egoera aldaketa adierazten duen inkoatibo funtziorik (22b):

(22) a. $\left[_{\text {Event }} \operatorname{INCH}\left(\left[\mathrm{ORIENT}\left(\left[_{\text {Thing }} \ldots\right],\left[{ }_{\text {Path }} \ldots\right]\right)\right]\right)\right]$

b. $\left[_{\text {State }}\right.$ ORIENT $\left(\left[_{\text {Thing }} \mathrm{x}\right],\left[\left[_{\text {Path }} \mathrm{y}\right]\right)\right]$

\section{Ibilbideak semantika kontzeptualean}

Jackendoff-ek (1983:165) hiru ibilbide mota bereizten ditu bere errepresentazio sisteman: batetik, ibilbide hesituak (bounded paths) deitzen dituenak, helmugadun ibilbideak (normalki alatibo batez lagunduak) eta iturburudun ibilbideak (normalki ablatibo batez lagunduak) biltzen dituztenak. Ibilbide mota honetan, lekua edo erreferentzia objektua ibilbidearen mutur batean dago (bukaeran, alatiboaren kasuan, eta abiaburuan ablatiboaren kasuan). Bestetik, baditugu Jackendoffek norabideak (directions) deitzen dituenak, zeinetan erreferentziazko objektua ez den ibilbidearen barnean gertatzen. Aldiz, ibilbidea luzatuz gero, erreferentziazko objektua haren barnean eroriko 
litzateke. -ri buruz edo -rantz bezalako atzizkiak era horretako ibilbideekin lotuta daude. (22)ko noranzko funtzioak norabideen saileko azpikasu bat dira. Hirugarren ibilbide mota Bidea (route) izenekoa litzateke. Holakoetan, erreferentziazko objektua ibilbidearen barneko puntu bati lotua agertzen da. Pasa (tu) bezalako aditz batek Bidea motako espazio adierazpideak hartzen ditu:

(23) a. Zaldizkoa etxetik pasa zen

b. Zaldizkoa tunelean barna pasa zen

c. Zaldizkoa errekaren hegitik pasa zen

Aipagai ditugun hizkeretan ikusi ditugun leku-datiboak noranzkoari lotuak dira, Jackendoffen zentzuan $(1983,1990)$. Leku-datiboa beraz oso ibilbide mota jakin bati dagokio: Gaiak Helmugarainoko bidea egiten ez duen kasuari. Era horretako leku argumentuak, Jomuga deitu ditugunak, datiboz markatuta agertzen dira gure korpusa lekuko den ekialdeko hizkeretan. Leku datibo horiek aldiberean aspektu markatzaile gisa ere agertzen zaizkigu, predikatu atelikoen jomuga abstraktua zehazten dutelarik.

\section{BIGARREN ATALA}

\section{Aspektu lexikoaren errepresentazio sintaktikoa}

Datiboaren lekuzko rola eta aspektuzkoa eventu egituraren errepresentazio xeheago baten bitartez uztar daitezke. Ramchand-en ikuspegian (2008), adizkiek lexikoian zehaztuta dakarte eventu-dekonposizioari dagozkion oinarrizko funtzioekin nola lotzen diren. Oinarrizko funtzio hauek izaera aspektuala dute, eta hiru dira: Abiatze funtzioa, Prozesu funtzioa eta Emaitza funtzioa. Ingelesez: Initiator, Process and Result. Funtzio horiek sintaxi egituran islatuak daude, eta elkarrekin agertzen direnean, honela egiten dute:

(24) $\left.\left[_{\text {InitiatorP }} \mathrm{DP}_{\text {Initiator }} \operatorname{Init}^{0}\left[_{\text {ProcessP }} \mathrm{DP}_{\text {Undergoer }} \operatorname{Proc}^{0}\left[_{\text {ResultP }} \mathrm{DP}_{\text {Resultee }} \operatorname{Res}^{0} \mathrm{XP}\right]\right]\right]\right]$

(24)ko eventu egiturak makrorol multzo batzu definitzen ditu: abiarazlea, jasalea eta emaitzaargumentua deituko ditugunak (ingelesez initiator, undergoer, eta resultee). Abiarazleak abiatze azpieventuak agertzen dituen ezaugarrien jabe dira, eta prozesu bati lotuta, prozesua abian jartzen duten entitate indibidualizatuak bilakatzen dira (Ramchand, 2008:53). Sintaktikoki, abiarazte funtzioaren subjektuak dira. Jasaleak haien egoera, posizioa edo mugimendua Ibilbide bati homomorfikoki lotua den entitate indibidualizatuak dira (ibidem, 53). Jasaleak prozesuen 'subjektuak' dira. Emaitza argumentuak emaitza egoeraren arabera definitzen diren entitate indibidualizatuak dira. Emaitza funtzioaren subjektuak dira. Argumentuek posizio bat baino gehiago har dezakete eventu konfigurazioan. Joan bezalako aditz baten kasuan, esate baterako, subjektua aldi berean abiarazlea eta jasalea da (ikus beherago).

Ebentu konfigurazioaren oinarrizko funtzioak eta haien argumentuez aparte, badira Ramchand-ek "Rhemes" deitzen dituenak. Ingelesezko terminologiari jarraikiko gatzaizkio eta euskaraz ere "remak" deituko ditugu. Remak "ez dira eventu-atal bati predikazio erlazio batez lotuak diren argumentuak, baizik eta oinarrizko predikatua modifikatuaz predikatua bera osatu egiten duten funtzioak" Nolabait esateko, rema batek predikatu konplexu bat osatzen du eventu egiturako atal jakin batekin (ibidem, 46). Esate baterako Prozesu burua Emaitza buruarekin lot daiteke predikatu teliko bat osatzeko, baina Postposizio Sintagma edo Determinatzaile Sintagma sinple batekin ere lot daiteke. Kasu horretan, PSk edo DSk ez dute beren azpieventu propioa ekartzen, baizik eta lotzen 
diren eventu atalaren modifikatzaile edo lagun gisa funtzionatzen dute. Ibilbide bat adierazten duten Postposizio edo Determinatzaile Sintagmek rema gisa iharduten dute.

\subsection{Adibide gisako kasu batzu}

Hartu gure leku-datiboak. Hesitugabeko Ibilbide bat denotatzen dute eta predikatu atelikoekin edo egoerekin lotzen dira. Leku datibozko predikatuek beraz ez dute Emaitza atalik, eta ez dute sintaxi egituran Emaitza bururik islatzen. Sistema honen baitan, leku datiboa deitu dugun hori Prozesu buruari lotzen zaio zuzenean. Har ditzagun ondoko prepausak adibide gisa (Hesitugabeko Ibilbide funtzioa Unbounded Path ingelesezko terminoaz ematen dugu egitura sintaktikoan):

(25) a. Jaun erretora badoa elizako atearen gakoari

b. Bainan herriak ez dezake ihardok ikastegiari

c. Jarraikiko naiz errosario sainduaren erraiteari

Aspektu egituraren aldetik, goiko perpausek honako egiturak dituzte:

$$
\begin{aligned}
& \text { a. }\left[_{\text {InitP }} \mathrm{DP}_{\text {Subj }} \operatorname{Init}^{0}\left[_{\text {ProcP }}\left(\mathrm{DP}_{\text {Subj }}\right) \operatorname{Proc}^{0}\left[_{\mathrm{UPath} / \mathrm{PP}} \mathrm{P}^{0}[\mathrm{DP}-\mathrm{Dat}]\right]\right]\right] \\
& \text { b. }\left[_{\text {InitP }} \mathrm{DP}_{\text {Subj }} \operatorname{Init}^{0}\left[_{\text {ProcP }} \operatorname{Proc}^{0}\left[_{\text {UPath/PP }} \mathrm{P}^{0}[\mathrm{DP}-\mathrm{Dat}]\right]\right]\right] \\
& \text { c. [ } \text { pro }_{\text {Subj }} \operatorname{Init}^{0}\left[\left(\operatorname{pro}_{\text {Subj }}\right)\left[_{\text {ProcP }} \operatorname{Proc}^{0}\left[_{\text {UPath/PP }} \mathrm{P}^{0}\left[\left[_{\text {EVENT }} \ldots\right]-\text { Dat }\right]\right]\right]\right]
\end{aligned}
$$

Lehen perpausa (25a), (26a) egiturari dagokio. Egitura horretan, Prozesuaren subjektua eta Abiarazte funtzioarena berbera dira (jaun erretora, gure kasuan). Joan bezalako aditz baten subjektua aldiberean eventuaren abiarazle eta joate prozesuaren jasalea da. Bigarren perpausak (25b) ez du jasale garbirik, Ramchand-ek rol honi ematen dion zentzuan (ikus goian), eta subjektua abiarazle hutsa da. Hirugarren perpausa (25c), (26c) egiturari dagokio. Joan aditzarekin bezala, subjektuak bi rol jasotzen ditu: bata abiarazle bezala, eta bestea jasale bezala. Azken kasu honetan, prozesu buruaren argumentua ez da izen sintagma sinple bat, baizik eta nominalizaturiko eventu bat.

Alatiboa datiboarekiko distribuzio osagarrian dagoenez, eta alatiboa mugimendu helmugadunari dagokionez beti (ibilbide hesitua denotatzen du), alatibodun aldaera honela adieraziko dugu:

(27) $\left[_{\text {InitP }} \mathrm{DP}_{\text {Subj }} \operatorname{Init}^{0}\left[_{\text {ProcP }}\left(\mathrm{DP}_{\text {Subj }}\right) \operatorname{Proc}^{0}\left[_{\text {BPath/PP }} \mathrm{P}_{\text {allative }}[\mathrm{DP}]\right]\right]\right]$

Telikotasuna, (27)k erakusten duen bezala, ez dago halabeharrez emaitza eventu baten presentziari lotua (hau Ramchanden sistemaren ezaugarri garrantzitsua da). Egoera predikatu hutsei dagokienez, emango dut zuzenean Abiarazle funtzioari lotzen zaizkiola. Ramchand-entzat Abiarazte funtzioa berez estatiboa da. Prozesuarekin lotzen denean bakarrik agertzen da mugimendu batekin lotua. (28a) bezalako perpaus batek honenbestez, (28b) bezalako egitura izango du (ikus Etxepare eta Oihartzabal, 2009):

(28) a. Balkoin bat, bideari emaiten duena

$$
\text { b. ... [ [nitP } \left.\left.\text { Balkoin bat }_{\text {Subj }} \text { Init }^{0}\left[_{\text {UPath/PP }} \mathrm{P}^{0}[\text { bidea-Dat }] \ldots\right]\right]\right]
$$

\section{HIRUGARREN ATALA}

\section{Txandakatzea}

(3)ren tankerako txandakatzea agertzen duten aditzak hainbat klasetakoak dira. Badira emate 
aditzak, hala nola eman, helarazi, eskeini, agindu; igortze eta hartze aditzak, hala nola eraman, ekarri, igorri, hedatu/zabaldu, erosi, saldu, eta barreatu; botatze aditzak, hala nola bota; eta mezutze-aditzak, hala nola erran, galdegin, izkribatu, aiphatu, kondatu. Zerrenda ez dirudi arbitrarioa denik: Gropen eta bestek (1989) ingelesezko DOC/PPC txandakatzerako ematen duten berbera da. Txandakatze hori (29)ko pareak erakusten duena da:

(29) a. I sent a letter to Mary

b. I sent Mary a letter

Hona hemen etsenplu batzu eman, igorri eta bota aditzekin:

(30) a. Kasik zituen guziak bertzeri emaiten zituen

(Etc. HH, 74)

b. Ondoko urtetan eman ziozkaten aita Chabagnori kargu batzu arras ohoragarriak (Etch. HH, 79)

(31) a. ... behako bat bota dezan ondoko lagunaren kopiari

(Etch. BEB, 9)

b. Doi-doiako begi-ukaldia botatu nion liburuari

(Etc.BEB, 66)

(32) a. Jeneralak depexa hau igorri zion bere andreari

b. Igorri zituzten Ameriketako buruzagieri sekulako... ageriak

(Etc. BEB, 69)

Ingelesez, eta baita beste hizkuntzetan ere, txandakatze hauek honako bi egitura kontzeptualak dituzte oinarrian (Harley, 2003):

(33) a. Eragindako ukaitea (Caused Possession): X-ren eraginez Y-k Z dauka

b. Eragindako mugimendua (Caused Motion): X-ren eraginez Z Y-n dago

(33a)n Y-k Hartzaile rola dauka. (33b)n, berriz, Helmugarena. ${ }^{6}$ Lan askotan (ikus Hale \& Keyser, 2002; Harley, 2003; Krifka, 1999, 2001; Oehrle, 1976, Pinker, 1989; Levin, 2008) proposatu izan da DOC eta PPC egiturek oinarri sintaktiko desberdina dutela. Harleyren arabera, txandakatzearen azpian ondoko eventu eskemak daude:

(34) DOC-aldaera (2003:46)

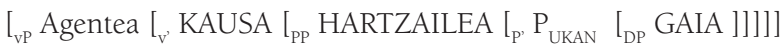

(35) To-dun aldaera (2003:46)

$\left[_{\mathrm{vP}}\right.$ Agentea [, KAUSA [ ${ }_{\mathrm{PP}}$ GAIA [, $\mathrm{P}_{\mathrm{LEKU}}\left[_{\mathrm{PP}}\right.$ to HELMUGA ]]]]]

Badira hiru desberdintasun nagusi (34) eta (35)en artean: (i) Gaia eta Helmuga/Hartzailea lotzen dituen adposizioaren izaera; (ii) Helmugaren izen edo adposizio izaera; (iii) Gaia eta Helmugaren arteko erlazio hierarkikoa. Azkenaz 8. atalean mintzatuko gara. Lehen bi desberdintasunak ondo uztartzen dira orainarte ikusi dugunarekin: batetik, komunztadurari begiratuta behintzat, iduri du datibozko sintagma batzuk adposizio sintagmak bezala portatzen direla. Bestetik, ematen

6. Harley-k ez du aintzat hartzen beste era bateko leku argumentuak posible izan daitezkeenik era horretako konfigurazioan. Euskarak, alatibo/datibo oposaketaren bitartez, Helmugak eta Jomugak eman ditzake bertan. Beste horrenbeste (35)en kasuan. 
du komunztaduragabeko datibo berezi horiek esanahiaren aldetik ere bereizten ahal direla: lekuzko rol bat adierazten dute. Eman dezagun beraz euskarazko (35)en ordaina "lekuzko datiboa" dela. Lekuzko datiboa, bestalde, postposizio sintagma bat da, aditzarekin komunztadura egiterik ez duena. ${ }^{7}$ Ramchand-en egitura baliatuaz, euskarako komunztaduragabeko kasuek honelako errepresentazioa izango lukete:

(36) $\quad \ldots\left[_{\text {InitP }} \mathrm{DP}_{\text {Subj }} \operatorname{Init}^{0}\left[_{\text {ProcP }} \mathrm{DP}_{\text {Obj }} \operatorname{Proc}^{0}\left[_{\mathrm{UPath} / \mathrm{PP}} \mathrm{P}^{0}[\mathrm{DP}\right.\right.\right.$-dat $\left.\left.\left.]\right]\right]\right]$

\section{Egitura aplikatiboak}

Orainarteko eztabaida osoa komunztatzen ez diren datiboei zuzendua izan da. Zer esan dezakegu komunztatzen den datiboaz?

\subsection{Hizki aplikatiboa}

Datibo komunztadura deitzen dugun hori berez bi gauza diferente dira:

(37) a. N-ator

1sA-erroa

b. N-ator-ki-zu

1sA-erroa-dat.au-2sD

(38) a. Naiz

$\operatorname{Lag}[1 s \mathrm{~s}]$

b. Natza-i-zu

aux[1sA-erroa-dat.au-2sD]

Komunztadura delakoak baditu, batetik, pertsona eta numeroari dagozkion markak, eta bestetik, egituran zehar osagarri bat dagoela adierazten duen morfema lotu bat, pertsona eta numeroaz apartekoa. Morfema horri datiboaren aurrekoa deituko diogu. ${ }^{8}$ (37b)-(38b) bezalako formek aditzera ematen dutena da datibozko argumentu komunztaduraduna euskaraz buru funtzional berezi baten bitartez baizik ezin zaiola lotu perpaus egiturari. Oihartzabalek (2008) proposatu du egitura hauek funtsean egitura aplikatiboak direla (ikus Peterson, 2007). Gure egingo dugu ideia hau.

\subsection{Txandakatzeak ez beti}

Interesgarria da hartara aurkitzea txandakatzea ez dela beti posible. Predikatu batzuek nahitaez komunztadura agertzen dute (ikus baitaere, Fernandez eta Ortiz de Urbina, 2008). Tartean parte/ osotasun erlazioak edota ezin besterenduzko posesioa adierazten duten predikatuak:

7. Honek era guzietako galderak sortzen ditu komunztaduragabeko datiboak hartzen dituzten predikatuen esanahiaren inguruan. Gogoratu euskarazko datibo komunztaduragabeek Jomuga rola gauzatzen dutela, eta hau ibilbide mota berezi bat dela, Helmugak gauzatzen duenetik bereizi duguna. Ez dugu hemen horretaz arduratzeko tarterik. Arazo horren analisiaren berri izan nahi duenak jo beza Etxepare eta Oihartzabal (2009) lanera.

8. Iduri luke morfema hori bera aski berria dela funtzio horretan, eta bere lehen agerpena laguntzaileetan gertatzen dela, ez forma sintetikoetan (ikus Etxepare eta Oihartzabal, prestatzen, eta Mounhole, 2008). 
(39) a. Aitari eskua hunki diot/*dut

b. Mahaiari hanka kendu diot/*dut

c. Piarresi muntra ebatsi diot/*dut

Fenomeno bera gertatzen da perpaus iragangaitzekin:

(40) Lehenagoko burho-egileari bihotza erdiratzen zaio/*da

(Etc.FE, 90)

Interes datiboa dakarten kasuek ere komunztadura behar izaten dute: ${ }^{9}$

(41) Mireni esneak gaindi egin dio/*du

Predikatu psikologikoek ere komunztadura behar dute:

(42) a. Joni bizia huts eta ilun iduri zaio/*da

b. Mireni ez zaio/*da gustatu

Laburbilduaz: igoera jasaten duten posesoreek, interes datiboek eta predikatu psikologikoetako subjektuek komunztadura eragiten dute halabeharrez (ikus baitaere Fernandez eta Ortiz de Urbina, 2008). Kasu hauek guziak zenbait ikerlarik "goiko aplikatiboak" deituriko sailaren barnean eman daitezke (ikus Pylkkanen, 2002; Cuervo, 2003; Jeong, 2006 besteak beste). Euskarazko komunztaduradun kasuak egitura aplikatiboak badira hau espero izatekoa da. Areago: goiko aplikatiboak baitira alatiboarekin eta orohar helmuga rolekin txandakatzen ez direnak (adierazten dituzten erlazioak ez baitira espazio erlazioen bitartez ematen ahal), naturalki segitzen da halakoetan komunztaduragabeko forma bat ezinezkoa izango dela.

\subsection{Erreferentzialtasun eskala eta komunztadura}

Erreferentzialtasunaren eskalan behean agertzen diren zenbait formek nekez eragiten dute komunztadurarik (ikus baitaere Fernandez eta Ortiz de Urbina, 2008). Sail horretan aurkitzen dira elkarkari eta bihurkariak (43a,c), eta e-hitzak (43b): ${ }^{10}$

(43) a. Bakea eman dezagun elgarri (LZ)

b. Nehori aipatu duzuia gure artekoa (LZ)

c. Bertzeen solasari beharria emanez, gara gure buruari sortzen (Sal.)

Erreferentzialtasunarekin loturiko era honetako murriztapenak ohikoak dira bai ingelesaren objektu biko egituretan (ikus Bresnan, 2006) bai egitura aplikatiboetan ere (Ikus Peterson, 2007).

9. Jean Haristchelhar jaunari eskertzen diogu adibide honen gaineko juizioa.

10. E-hitza terminoaz izendatuko ditugu bestela polaritatedun hitzak bezala ezagunak direnak: ezer, inor, inon, eta gainerakoak. Mitxelenaren arabera (1968) ezezko partikularen eta izenordain zehaztugabe baten konbinaketaz sortuak dira. E-hitzak beraz ezezkoaren laguntzaz eraturiko izenordainak dira. 


\subsection{Laburbilduaz}

Komunztaduradun datiboak egitura aplikatiboak badira, delako komunztadura txandakatzea bi egitura desberdinen erabilerari zor zaio: batetik, postposizio izaera duen eta lekuzko rol bat adierazten duen datiboari dagokiona; bestetik, egitura aplikatiboari dagokiona. Azken hau, komunztaduraz aparte, datiboaren aurrekoa deitu dugun hizki baten bitartez markatzen da aditz jokatuan.

\section{Analisiaren predikzio batzu}

\subsection{Bi datiboko egiturak}

Komunztadura txandakatzea azpiko bi egitura diferenteren erabilerari badagokio eta egitura horiek elkarrekin konbina badaitezke posible izan behar luke, printzipioz, datibo bat baino gehiagoko egiturak aurkitzea (japonieraz bezala, Miyagawa eta Tsujioka, 2004). Predikzioa betetzen da:

(44) a. Traidoreari begitarteari ohartuz...

b. Hurbildu nion urrikalmenduzko seinalea ezpaineri

\subsection{Perpaus egituran non}

Ikus ondoko kontrastea:

(45) a. Jonek igorri duena da liburu bat anaiari

b. Jonek igorri diona da liburu bat anaiari

Kontraste honek esplikazio natural bat aurkitzen du guk emandako analisian. Komunztaduragabeko datiboa postposizio egitura bati dagokio. Postposizio horrek hesitugabeko ibilbide bat denotatzen du eta prozesu buruari lotzen zaio zuzenean:

(46) a. $\left[_{\text {InitP }} \mathrm{DP}_{\text {Subj }} \operatorname{Init}^{0}\left[_{\text {ProcP }} \mathrm{DP}_{\text {Obj }} \operatorname{Proc}^{0}\left[_{\mathrm{UPath} / \mathrm{PP}} \mathrm{P}^{0}[\mathrm{DP} \mathrm{Goal}\right.\right.\right.$-Dat $\left.\left.\left.]\right]\right]\right]->$ b. $\left[_{\text {InitP }} \mathrm{DP}_{\text {Subj }}\right.$ Init $\left.\left.^{0}+\operatorname{Proc}_{\text {ProcP }} \mathrm{DP}_{\text {Obj }}\left(\mathrm{Proc}^{0}\right)\left[_{\mathrm{UPath} / \mathrm{PP}} \mathrm{P}^{0}\left[\mathrm{DP}_{\text {Goal }}-\mathrm{Dat}\right]\right]\right]\right]$

Egitura honetan Objektua eta Zehar Osagarria osagai baten barnean elkarrekin mugi daitezke (46a). Egitura aplikatiboan berriz zehar osagarria Aditz Sintagmatik kanpora mugitzen da (morfema aplikatiboa forma jokatuari lotzen zaio ez forma lexikoari):

$$
\begin{aligned}
& \text { a. }\left[\left[_{\text {ApplP }} A \operatorname{Apl}^{0}\left[_{\text {InitP }} \mathrm{DP}_{\text {Subj }} \operatorname{Init}^{0}\left[_{\text {ProcP }} \mathrm{DP}_{\text {Obj }} \operatorname{Proc}^{0}\left[_{\text {Result }} \operatorname{Res}^{0}[\mathrm{DP} \text { Goal } \text {-Dat }]\right]\right]\right]->\right.\right.
\end{aligned}
$$

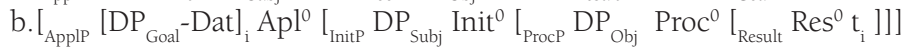

Datibozko argumentua proiekzio aplikatibora igotzen baldin bada, ez dago osagai bakar bat ere zehar osagarria eta objektua elkarrekin eman ditzakeenik aditza kanpoan utzita. Datu honi ondoko beste hau gaineratu behar zaio: zenbait hiztunentzat behintzat, komunztaduragabeko datiboaren leku naturala objektuaren ondoren da, eta aditzaren atzetik (M. Aurnague, komunikazio pertsonala), komunztaduradunekin ez bezala (ikus Elordieta, 2001; Fernandez, 1997):

(48) Jonek igorri du letra bat Mireni 


\section{Behin behineko ondorioak}

Ikusi dugunaren arabera, ekialdeko zenbait hizkerek badituzte bi egitura ditrantsitibo klase: bata egitura aplikatibo bat da, aditz sintagmaz kanpoko proiekzio funtzional bat baliatzen duena; bestea aditz sintagmaren barnekoa, postposizio bidezkoa dei daitekeena, eta hesitugabeko ibilbide bat denotatzen duena. Azken hau "lekuzko datiboak" deitu ditugun bestelako kontestuetan ere ager daiteke.

\section{Erreferentziak}

\section{Korpusa}

Etcheberry, J.B. (1966) Frantziako Erregina. Bayonne:Imprimerie Cordeliers.

Etcheberry, J.B. (1969) Obrak Mintzo. Bayonne:Imprimerie Cordeliers.

Etcheberry, J.B. (1978) Han-Hemenka. Bayonne:Imprimerie Cordeliers.

Etcheberry, J.B. (1980) Berriz Ere Beretarik. Bayonne:Imprimerie Cordeliers.

Larzabal, Piarres [1991-1998] Lan Guztiak. Piarres Xarritonen edizioa. VIII ale. Donostia: Elkar.

Sallaberry, Etienne (1978) Ene sinestea. Itxaropena: Zarautz.

\section{Teoria aldetiko zenbait erreferentzia}

Albizu, Pablo (1997a) "Generalized person-case constraint: A case for a syntax-driven inflectional morphology" In A. Mendikoetxea and M. Uribe-Etxebarria (eds) Theoretical Issues in the Morphology-Syntax Interface. Supplements of the Anuario del Seminario Julio de Urquijo. Donostia: Gipuzkoako Foru Aldundia. 1-34.

Albizu, Pablo (1997b) The syntax of person agreement. Unpublished PhD dissertation. USC. Los Angeles.

Albizu, Pablo (2001) "Datibo sintagmen egitura sintaktikoaren inguruan:eztabaidarako oinarrizko zenbait datu" In Beatriz Fernandez and Pablo Albizu (eds) Kasu eta Komunztaduraren GaineanOn Case and Agreement. Bilbao:University of the Basque Country. 49-70.

Anagnastopoulou, E. (2003) The syntax of ditransitives: Evidence from clitics. Berlin:Mouton.

Arregi, E. eta J. Ormazabal (2003) "Aditz ditrantsitiboen barne-egitura" In J.M. Makatzaga and B. Oyharçabal (eds) P. Lafitteren sortzearen mendemugako biltzarra. Gramatika gaiak. Iker-14 (I). Bilbo: Euskaltzaindia. 119-136.

Elordieta, Arantzazu (2001) Verb Movement and Constituent Permutation in Basque. Leiden: LOT Publications.

Etxepare, Ricardo (2003) "Valency and Argument Structure in the Basque Verb" In Jose Ignacio Hualde and Jon Ortiz de Urbina (eds) A Grammar of Basque. Mouton Grammar Library 26. Berlin: Mouton. 363-425.

Etxepare, Ricardo eta Bernat Oihartzabal (2009) "Optional dative agreement in eastern Basque" Ms. IKER.

Etxepare, Ricardo eta Bernat Oihartzabal (prestatzen) "Datibo komunztadura diakronian"

Etxepare, Ricardo (2008) Optional Agreement Phenomena in Basque. Habilitation Thesis. IKER, CNRS.

Etxepare, Ricardo (prestatzen) "Complex Postpositional Structures in Basque" Ms. IKER.

Fernandez, Beatriz (1997) Egiturazko Kasuaren Erkaketa Euskaraz. PhD dissertation, University of 
the Basque Country.

Fernandez, Beatriz eta Jon Ortiz de Urbina (2008) "Datibo komunztadura ekialdeko hizkeretan". Ms. University of the Basque Country and University of Deusto.

Gropen, J. et alia (1989) "The Learnability and Acquisition of the Dative Alternation inEnglish" Language 65:203-257.

Hale, K. and S.J. Keyser (2002) Prolegomenon to a Theory of Argument Structure.Cambridge: MIT Press.

Harley, Heidi (2003) "Possession and the double object construction". Ms. University of Arizona.

Jackendoff, Ray (1983) Semantics and Cognition. Cambridge:MIT Press.

Jackendoff, Ray (1990) Semantic Structures. Cambridge: MIT Press.

Lafitte, Pierre (1944) Grammaire Basque. Reprint. Baiona:Elkar [1979]

Lafon, René (1944) Le Système du verbe basque au XVIè siècle. Reprint. Baiona:Elkar. 1980.

Laka, Itziar (1993) «The structure of inflection: a case study in X0-syntax" In J.I.Hualde and Jon Ortiz de Urbina (eds) Generative Studies in Basque Linguistics. Amsterdam: John Bernjamins.

Levin, B. (2004) "Verbs and Constructions: Where Next?" Handout. WECOL, USC, Los Angeles.

Levin, B. (2008) "Dative Verbs: A crosslinguistic Perspective" Handout. Stanford University.

Marantz, Alec (1993) "Implications of Asymmetries in Double Object Constructions" In S.A.Mchombo (ed) Theoretical Aspects of Bantu Grammar. Stanford:CSLI Publications. 113-150.

Miyagawa, S. and T. Tsujioka (2004) "Argument structure and ditransitive verbs in Japanese" Journal of East Asian Linguistics 13:1-38.

Mounole, C. (agertzekoa) "Evolution of the transitive verbs in Basque and appearance of datively marked patients". In Gilles Authier (arg) Ergativity, Transitivity and Voice. Berlin: Mouton.

Oehrle, R.T. (1978) The Grammatical Status of the English Dative Alternation. PhD dissertation. Cambridge, MIT.

Oyharçabal, Bernard (2008) "Argument Structure Building: Dative Applicative Heads in Basque" Paper presented in the Workshop on Argument Structure and Syntactic Relations. Vitoria-Gasteiz.

Ormazabal, J. and J. Romero (1998) "On the syntactic nature of the me-lui and the Person-Case Constraint" Anuario del Seminario Julio de Urquijo 32:415-434.

Ormazabal, J. and J. Romero (2001) "A brief description of some agreement restrictions" In B.Fernandez and P. Albizu (eds) Kasu eta Komunztaduraren Gainean-On Case and Agreement. Bilbao:University of the Basque Country. 215-241.

Peterson, D.A. (2007) Applicative Constructions. Oxford:Oxford University Press.

Pinker, S. (1989) Learnability and Cognition. Cambridge:MIT Press.

Pylkkanen, L. (2002) Introducing Arguments. Unpublished PhD dissertation. MIT.

Ramchand, G. (2008) Verb Meaning and the Lexicon. Cambridge: Cambridge University Press.

Rebuschi, G. (1982) Structure de l'énoncé en Basque. Doctoral dissertation, Paris (Coll. ERA-642, Laboratoire de Linguistique Formelle et Département de Recherches Linguistiques. Paris VII.

Rebuschi, G. (1999) «Le complexe verbal basque: un regard universaliste» Lapurdum

Rezac, M. (2006) Basque Morphosyntax. Ms. University of Nantes/CNRS.

Zwarts, Joost (2005) "Prepositional Aspect and the Algebra of Paths" Linguistics and Philosophy 28: 739-779. 